\title{
Design the Boost Converter of Solar Photovoltaic Power System
}

\author{
Alaa bunyan mghames \\ Faculty of Engineering \\ Electrical Engineering Department \\ Mansoura University \\ alaabunyan@gmail.com \\ Dr. Ahmed Eid Moussa Shahin \\ Faculty of Engineering \\ Electrical Engineering Department \\ Mansoura University
}

\author{
Prof. Dr. saad saad El Eskander \\ Faculty of Engineering \\ Electrical Engineering Department \\ Mansoura University
}

\author{
Prof. Dr. Mohamed Adel Elsayess \\ Faculty of Engineering \\ Electrical Engineering Department \\ Mansoura University
}

\begin{abstract}
In this paper, DC modulators are designed that raise the constant voltage to the operating values and that feed the loads The electrical elements that make up the lifter are designed for DC voltage. The main components are designed, which consists of three main phases connected in series with each other. The first stage contains an electric coil that is designed with specific specifications according to the requirements of the load. It also contains a suitable IGBT electronic key selected according to the specifications of the load. The three phases that make up the device are completely identical. The operating strategy of the various electronic switches is compatible with the load operation strategy and specifications. Feeding the step-up device from a group of batteries designed according to the needs of the load. And connect the batteries in series according to the needs of the designer. And the output voltage of the device is controlled at a constant value. This device feeds the DC/AC voltage changer, which in turn feeds the previous load. Determine the level of constant voltage 320VDC to obtain an alternating voltage of 220VAC. The electronic switches are controlled at each stage according to the strategy designed for operation. This strategy was programmed and placed in the memory of the microcontroller, where the Arduino was chosen for this purpose. This type was chosen for its simplicity and ease of programming and operation.
\end{abstract}

\section{INTRODUCTION}

Through this chapter we take up stages step up converter is design. The design converter is multi stage type. It contents three stages with three coils. The converter always three diode each of which connects with each coil [1]. The converter contents three switches of IGBT type. The switch is selected based upon the selected frequency of operation. The converter circuit has a capacitor connected with it. The converter coils are charged through switches from bank of batteries of $48 \mathrm{~V}$ as the switches are ON conditions. Hence; the coils are in parallel from during the charging conditions so; each coil of the converter is charged from 48 VDC supply (batteries) [2-3]. On the other hand; the converter coils discharger the energy in the load as the connected in the series from. So; the IGBTs are in OFF conditions. So that; the load voltage becomes the sum of voltages upon the stages coils pules. So; the converter coils are charged together is the connected is parallel supply from $48 \mathrm{~V}$ [4-5]. so; the coil voltage rises to $48 \mathrm{~V}$. through the discharge condition the coil are together connected in series with the supply voltage.so; the load voltage reaches to in ( $\mathrm{n} *$ supply voltage + supply voltage) [6]. In means that the load voltage goes up to the design voltage (360) [7-8]. During the discharge conditions of the converter coils; the voltage of coil intents from several times of supply voltage (48). Hence; open circuit voltage of the design converter reached up to $600 \mathrm{~V}$. The converter is loaded; its voltage full down [9]. The last voltage depended upon the load voltage these phenomena through this chapter.

\section{BOOST CONVERTER CIRCUITS.}

The boost converter consists of coils, diodes, switches and capacitor. Figure (1) the connection diagram of the converter circuit during charging condition.

Fig: (1) Represent the boost converter circuit during charging.

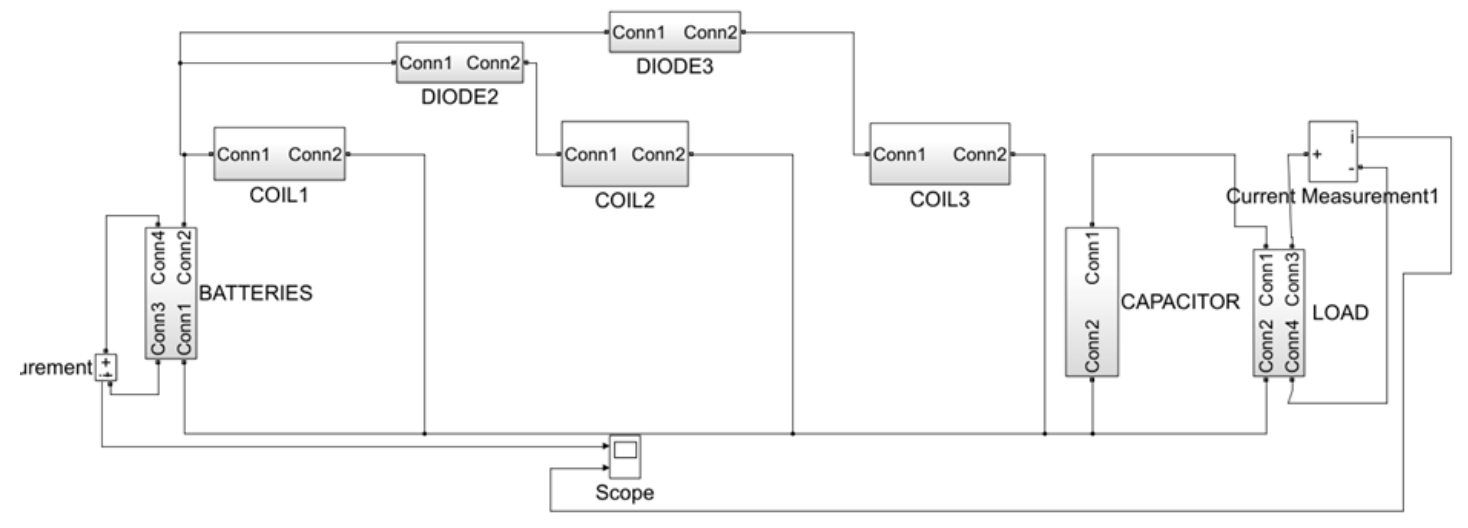

Fig. 1. Converter circuit during charging condition 


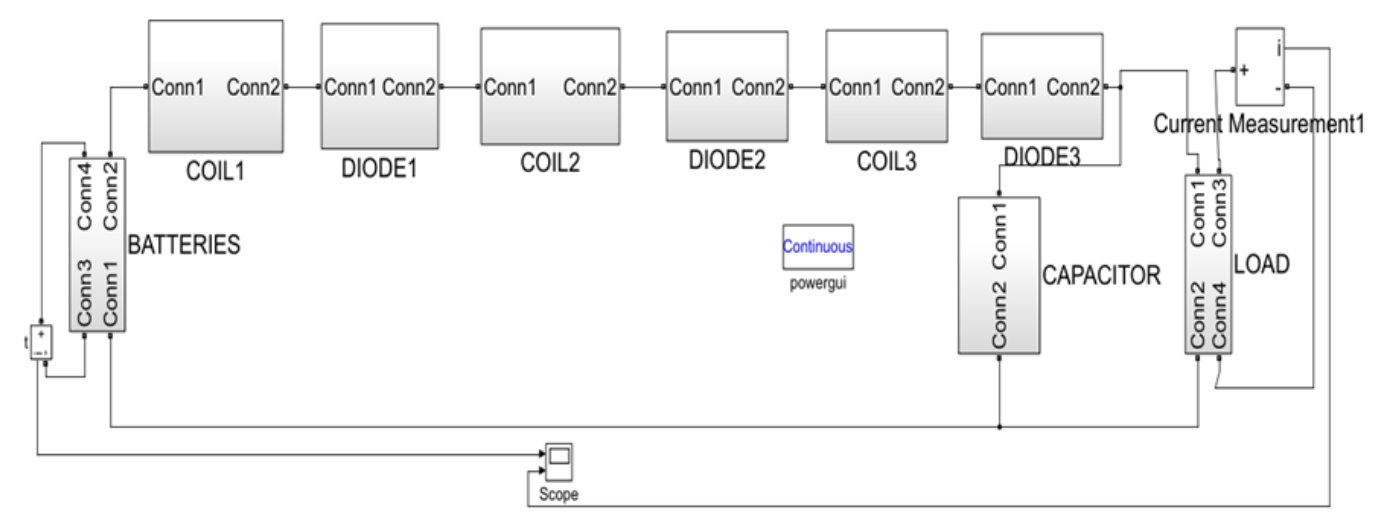

Fig. 2. Represent the connection diagram of the converter element during the discharging condition

\section{BOOST CONVERTER DESIGN.}

The design of boost converter is initiated by selection of the duty cycle. Its selects in the range duty cycle ( 0.6 to 0.75 ). The last range represent the best range operation of the selected IGBTs in the electronic of 0.7 duty cycle near to the optimum is selected during the converter design. Selection of the coil number of stages $(\mathrm{N})$ depend on output voltage (VO), input voltage (VIN) and duty cycle [10-11]. VO is selected with a value suitable to operation input voltage of the solar energy [12]. These value is selected as 360 VDC, the last output value of the design step up dc converter is very suitable to the input of the solar inverter in market [13].

$$
v o=v s * \frac{1+(n-1) D}{1-D}
$$

Where ;

Vo : is the converter output DC voltage.

$\mathrm{Vs}$ :is the converter input DC voltage.

$\mathrm{D}:$ is the duty cycle.

$\mathrm{n}$ : is the number of converter stages.

So; from the last equation the design value is calculated as three stages $(n=3)$. The diodes are selected based upon there forward current as well as reverse voltages of the switches (IGBTs) are selected based up there switching frequency [14-15].

The inductance of the designed converter circuit is calculated as;

$$
L=(D R) /\left(\delta f * \frac{1+(n-1) D}{1-D}\right)
$$

Where;

$\mathrm{D}:$ is the duty cycle.

$\mathrm{R}$ : is the load resistance.

\section{$\delta$ : is the current variation}

$$
(0.05<\delta<0.4) \text {. }
$$

$\mathrm{f}=$ frequency (IGBTs) is equal $10 \mathrm{kHz}$.

The size of the capacitor is designed from the following equation :-

$$
C=D / R f(\Delta v o / v o)
$$

$\Delta v o$ is the allowable variation in load voltage, it is preferable to be $1 \%$ or $2 \%$ of the load Voltage

\section{COIL DESIGN}

The coil is designed with iron core or air core. In the circuit the selection of the iron core is the best selection. This is due to fact the iron core coil storages more energy as small size than the air core coil [16-17]. So the coil designed for the design of converter has the following photograph:-

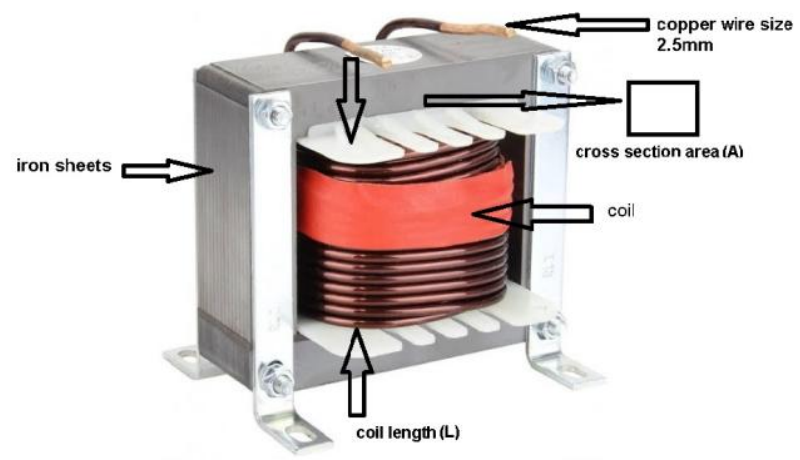

Fig. 3. Iron core of the designed coil

Fig.(3): Represent the Iron core of the design coil. This is figure shows that, the designed Iron core is close best for magnetic field generated then the coil. The magnetic field generated then the coil has two passes [18-19]. Through this is pass the magnetic field takes place within them. So, the magnetic field passes through Irion with high permeability $\left(M_{r}\right)$ than the Air [20-21]. This mean that this coil storages more electrical energy than the Iron core coil. So, that this selected as best element of the design converter.

\section{Iron core dimension.}

The selection of the Iron core dimension. The selected Iron core dimension is the length of iron core 1 as well as the core section [22-24]; A the ratio of (A / 1) is the determined as following:-

Is the determine by using the following equation:-

$$
\begin{aligned}
& L=(N \emptyset) / I \\
& \varnothing=B * A \\
& B=M * H \\
& H=N I / l \\
& L=((N * B * A)) / I
\end{aligned}
$$

(8) from (4)(5) 


$$
\begin{aligned}
& L=(N * M * H * A) / I \\
& L=\left(N^{\wedge} 2 * M\right) *(A / l)
\end{aligned}
$$

Where;

$\mathrm{B}$ : is the magnetic flux density through the core.

$\phi$ : is magnetic flux the core.

$\mathrm{I}$ : is the load current.

$\mathrm{N}$ : is the number coil turns.

$\mathrm{H}$ : is the strength of the magnetic field.

$l$ : is the coil length.

$A:$ is the cross section area the core.

By the best selection of the ratio $(\mathrm{A} / \mathrm{l})$. the number of turns the design of coil this obtain from equation (10). So, the core and the coil in the flowing table (1)

TABLE I. SPECIFICATION OF THE COIL :-

\begin{tabular}{|l|l|l|l|l|l|}
\hline $\mathrm{L}(\mathrm{mH})$ & $\mathrm{N}($ turn $)$ & $\mathrm{A}\left(\mathrm{CM}^{\wedge} 2\right)$ &. $\mathrm{l}(\mathrm{CM})$ &. $\mathrm{d}(\mathrm{MM})$ & $\mathrm{I}(\mathrm{amps})$ \\
\hline 10 & 40 & 12 & 7 & 2.5 & 10 \\
\hline
\end{tabular}

V. Selection the OUtPut Voltage OF the Design CONVERTER.

The designed output voltage of the converter $(220 * \sqrt{2})=320$ vac. this voltage is required to operate the solar inverter [25]. So several steps of converter are designed.

\section{MONO STEP UP BOOST CONVERTER.}

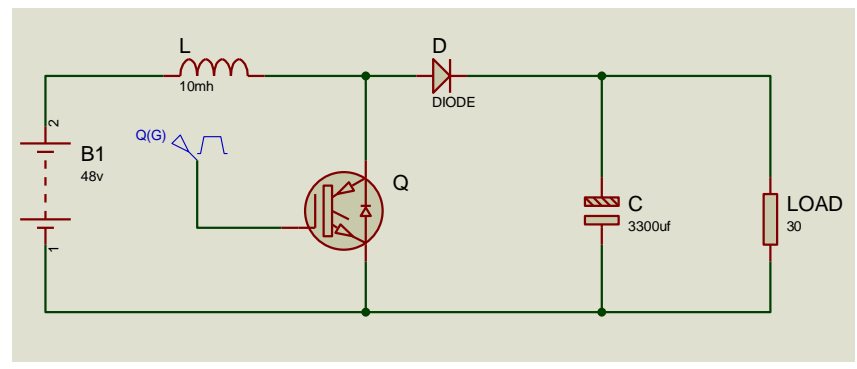

Fig. 4. Mono step converter

Fig.(4): Shows the design of the mono step converter circuit which contains the DC supply of four series batteries each of which of $12 \mathrm{VDC}$, and the following basic elements: VDC.

DC supply of four series batteries each of which of 12

$\mathrm{L}$ : Inductance of the coil.

$\mathrm{D}$ : The diode prevents the reverse current during discharge condition,

Q : The electronic switch of the type IGBTs used to charge the coil from the supply during in finite in travel (Ton),

$\mathrm{C}$ : is the capacitor connected to the converter terminals, and

LOAD : The electrical supplied load.

A. Mono step up converter (MSC) switch.

The MCS has one switch uses for switching its circuit to charge and discharge the coil. The using switch is selected of
IGBT type. The switch IGBT is in IC form. The IC of previous switch has two transistor coupled which each either. The two transistor of IC are (PJT) bipolar junction transistor as well as MOSFET. The input to IC of IGBT switch is in the MOSFET transistor so the pulse triggers the IGBT input to the MOSFET gate. On the other hand, the output takes from the IGBT out of its Collector (C) and Emitter (E). Hence, the IGBT type of switch has three terminals. This terminal are named the is GATE $(\mathrm{G})$, Collector ( C ) and Emitter (E). This type of switch is a good choose for the selection operation. It has very high input resistance. So the current drawn by the switch is nearly equal zero. On the other hand the output of the switch low resistance because the output is taken from the output terminal of the PJT transistor, this type of transistor is trigger by generating a pulse with amplitude 12 VDC during the switch off condition, the drive circuit generates negative pulse of 12 VDC. The negative pulse is generated by the drive circuit fasts the switch off time of the transistor. So; its internal capacities discharge there charges rapidly. The gate terminal of IGBT must be connected with resistor of $10 \mathrm{~K} \mathrm{ohm}$. This resistance connects between the gate emitter terminal of the IGBT switch the purpose of using this resistance with. The last value is to prevent the revers current passing through the transistor. The voltage drop upon the last register must not increases of $\mathrm{V}_{\mathrm{Gon}}$ of the using transistor.

\section{TABLE II. IGBT SPECIFICATIONS (2MBI100U4A-120)}

\begin{tabular}{|l|l|l|l|l|}
\hline $\mathrm{I}_{\mathrm{C}}$ & $\mathrm{V}_{\mathrm{CE}(\mathrm{SAT})}$ & $\mathrm{V}_{\mathrm{GE} \text { (threshold) }}$ & $\mathrm{V}_{\mathrm{f}(\text { forward })}$ & $\mathrm{V}_{\mathrm{GE} \min (\text { th) }}$ \\
\hline $100 \mathrm{~A}$ & $2.2 \mathrm{~V}$ & $8.5 \mathrm{~A}$ & $1.95 \mathrm{~V}$ & $4.5 \mathrm{~V}$ \\
\hline
\end{tabular}
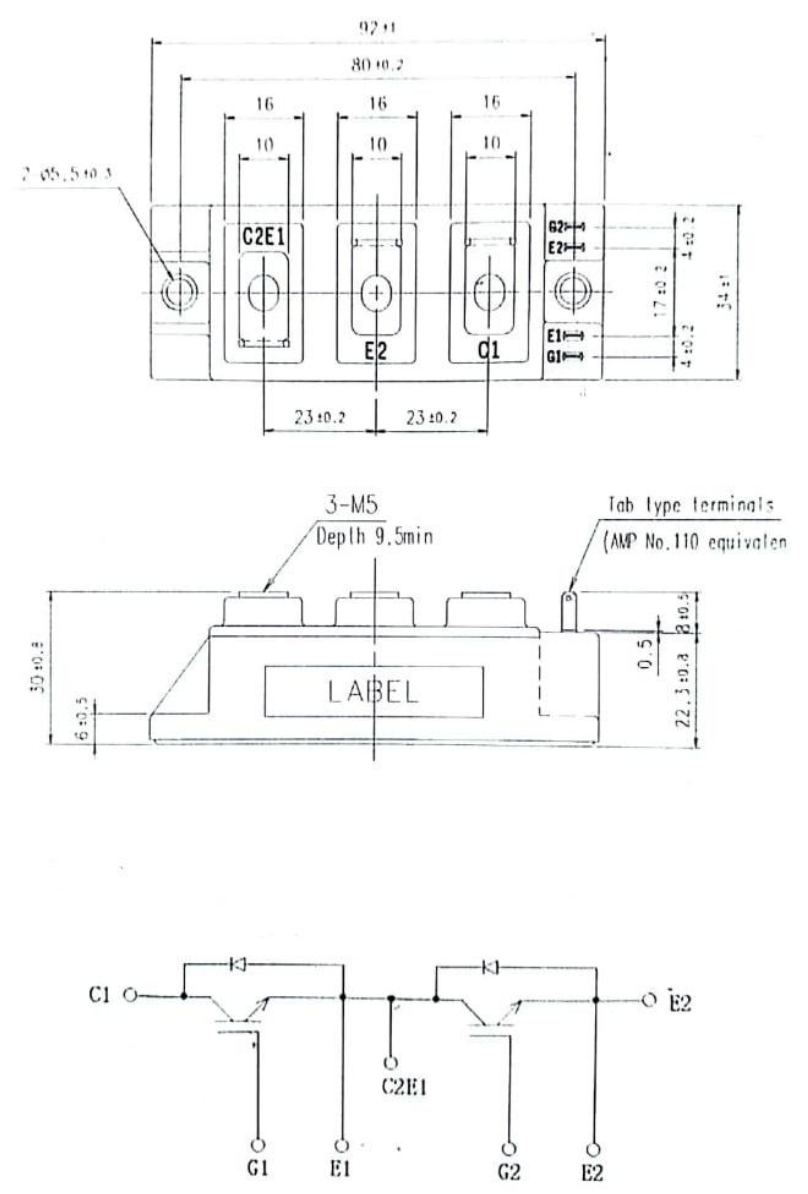

Fig. 5. Block diagram and wiring diagram of [IGBT (2MBI200U4A-120)] 


\section{B. Drive circuit (TLP).}

Drive circuit for IGBTs is the circuit which supply the switch gate with the power needed to design the switch drive circuit as in [26]. In the proposed DC/DC converter, the driver circuit depends mainly on TLP250 or TLP350 IC. This integrated circuit is an optically isolated driver, meaning that the input and output are optically isolated TLP250/350 has an input stage and a power supply connection.

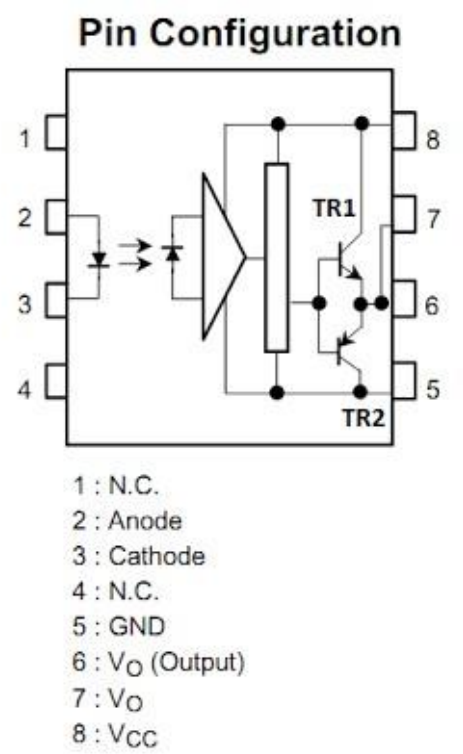

Fig. 6. TLP250 pen configurations

Fig: (6): Show the schematic diagram of TLP250 driver circuit which is proposed in the DC/DC converter. Firstly, designing the input stage of TLP250, the input stage consists of led. Led has an input forward voltage $(1.6 \mathrm{~V})$ and a peak forward current (10 mA). Therefore,R1 will equal $320 \mathrm{ohm}$.

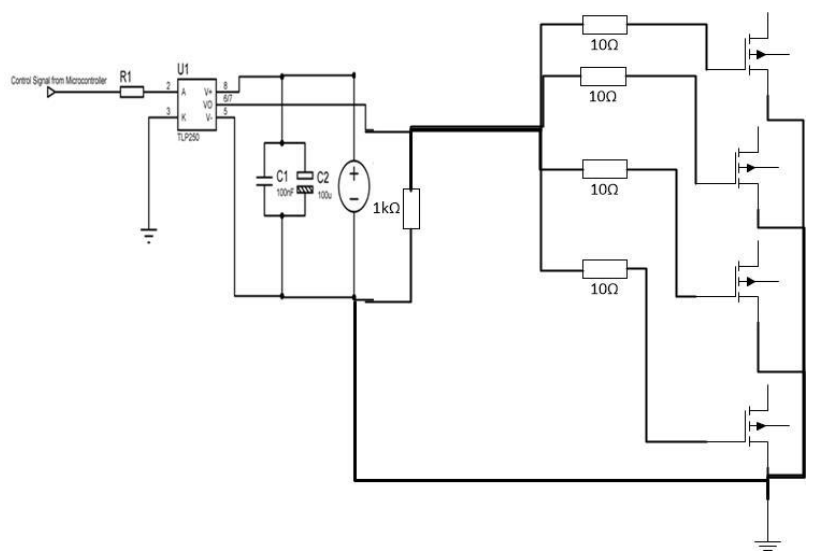

Fig. 7. Schematic of drive circuit using TLP250

From datasheet of the opt-coupler, the maximum collector current of output transistors is $7 \mathrm{~mA}$. Therefore, two transistors Q1, Q2 are required to protect the optcoupler. The TLP250, being an opt-coupler driver, has generally moderate propagation delays. The propagation postpone time will regularly lie somewhere in a range between $.15 \mu \mathrm{s}$ and $0.5 \mu \mathrm{s}$. The datasheet indicates the maximum working frequency to be $25 \mathrm{kHz}$. Thusly, it is reasonable for the proposed DC/DC converter, in which the TLP250 is utilized for frequency with a value of $10 \mathrm{kHz}$. A $0.1 \mu \mathrm{F}$ detour capacitor ought to be associated between stick 8 and stick 5. This capacitor balances out the task of the high straight voltage gain in the TLP250. Inability to give this capacitor may impede the switching polarity. The capacitor ought to be set as near the TLP250 as could. Included $100 \mu \mathrm{F}$ is for smoothing, as a mass capacitor. The datasheet of TLP250. Fig. (7) Shows the connection of the drive circuit using TLP250 and designed series and parallel gate resistors.

\section{Basing Supply.}

The TLP drive circuit is supplied from DC supply of three terminal $+12,0$ and -12 VDC. The basing voltage of the TLP; the IC of type (IA1212S/MC34063) is used. This type of IC is supplied from battery of 12VDC. The output of this type of ICs gives the output of (-/+ 12 VDC) as well as a zero. This output is suitable for basing the drive circuit of TLP type. Hence; the output of TLP drive circuit has values +12 VDC pulses [27]. The last pulses are more suitable for triggering the IGBT switch during the $\mathrm{ON}$ and OFF states.

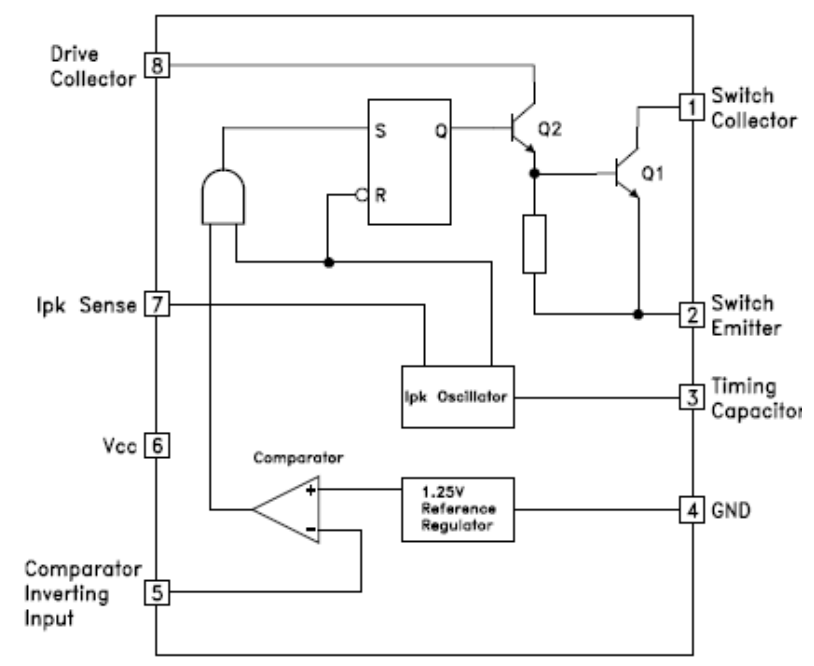

Fig. 8. Schematic diagram of the IC of type (MC34063)

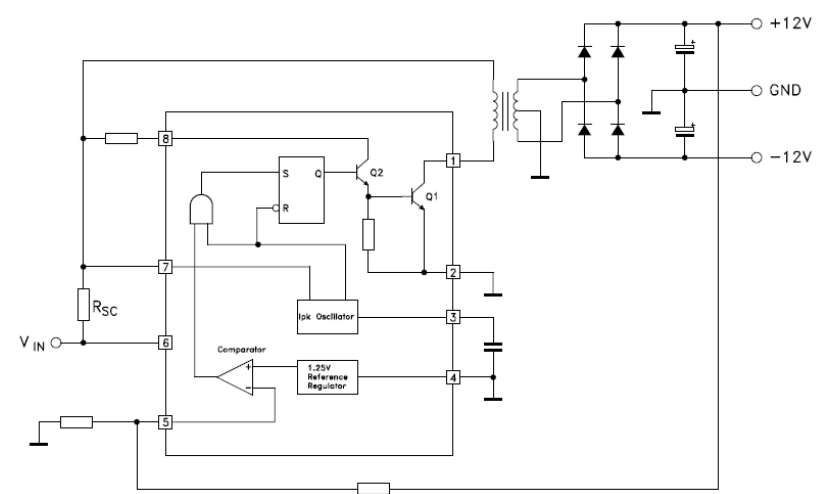

Fig. 9. Schematic diagram of the IC (MC34063) bases the drive circuit

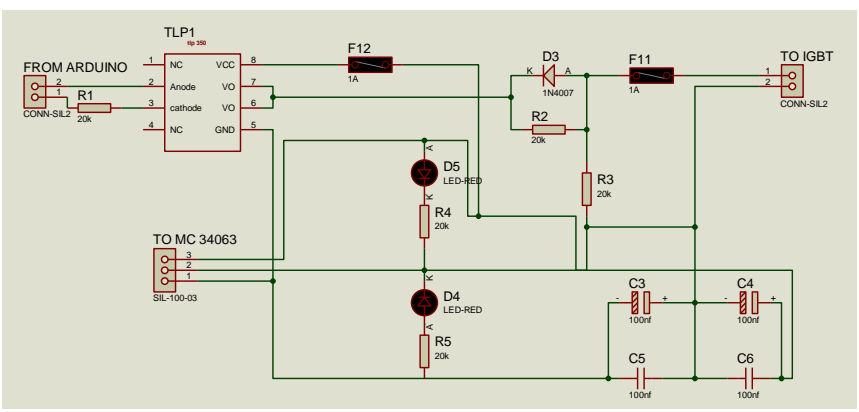

Fig. 10. Wiring diagram of basing supply 


\section{Microcomputer (micro controller).}

The microcomputer of type ARDUINO is used to generator from of pulses input to the TLP. The amplitude of the pulse output of the ARDUINO is 5VDC only the ARDUINO output pluses is generated according to specification strategy. The strategy is design according to the operation of the converter switch. The switch operates ON and OFF according to the value used of duty cycle (0.7) with frequency of $(10 \mathrm{kH})$. The ARDUINO has future than the either pic that ; its auxiliary circuits (oscillator, capacitor, set, reset SW and step down converter from 9VDC to 5VDC) are built inside it. So; it's using is very easy than the other PICs. On the other hand; the design operating strategy software is loaded to ARDUINO directly from the PC to ARDUINO through USB cable. The strategy is writing by using very sample codes suitable to the ARDUINO type [28]. The ARDUINO used is type (ARDUINO UNO). It has (30 pins). The ARDUINO UNO pins fragment into four groups. These groups are as fallowing; group one (analog input) has five pins (A0, A1, A2, A3, A4 and A5) this pins operates as the input analog pins. Groups two (power) this pins operates power supply to pin (5vdc, $3.3 \mathrm{vdc}$ and GND). Groups three (DIGITAL-PWM) has pins are fourteen (output or input pins). Groups four (set and reset switch). The ARDUINO (pic) microcontroller in illustrates the execution of the software with in the basing voltage start up. Is this instant, pin 13 of output / input group of the pic. Connected with ground through resistance is $1 \mathrm{k}$ ohm. The last resistor connected with pin 13 is used with in value (its selects as $1 \mathrm{k}$ ohm). For limiting, the current passes from pin 13 to ground. Its means that; pin 13 becomes low during the execution of the ARDUINO software program. Pin 13 is connected with the output of the device (converter). The converter contents three switches are trigger similar. Hence ; the trigger from one pin of the input / output group of the pic. The trigger pin of the pic has no. (ARD. Pin 6) of the input / output group of the pic. The last pin is connected to the input of the TLP. The TLP out is taken from three output pins. Each pin of the TLP out gives pulse with amplitude of +/- 15 voltages with frequency to $10 \mathrm{kHz}$. The duty cycle of the TLP output pulses is limited to a value such that the output voltage of the converter is in the range of $340>=$ Vout $>=320$. The limits of the converter output voltage is pass feed by the software designed with in the pic.

\section{Design THE DC/DC Boost CONVERTER CiRCUIT.}

The DC / DC converter circuit contains the element in the circuit described in the above get in the circuit of the device are connected together to give the designed step up converter. Fig.(11):. shows the converter circuit.

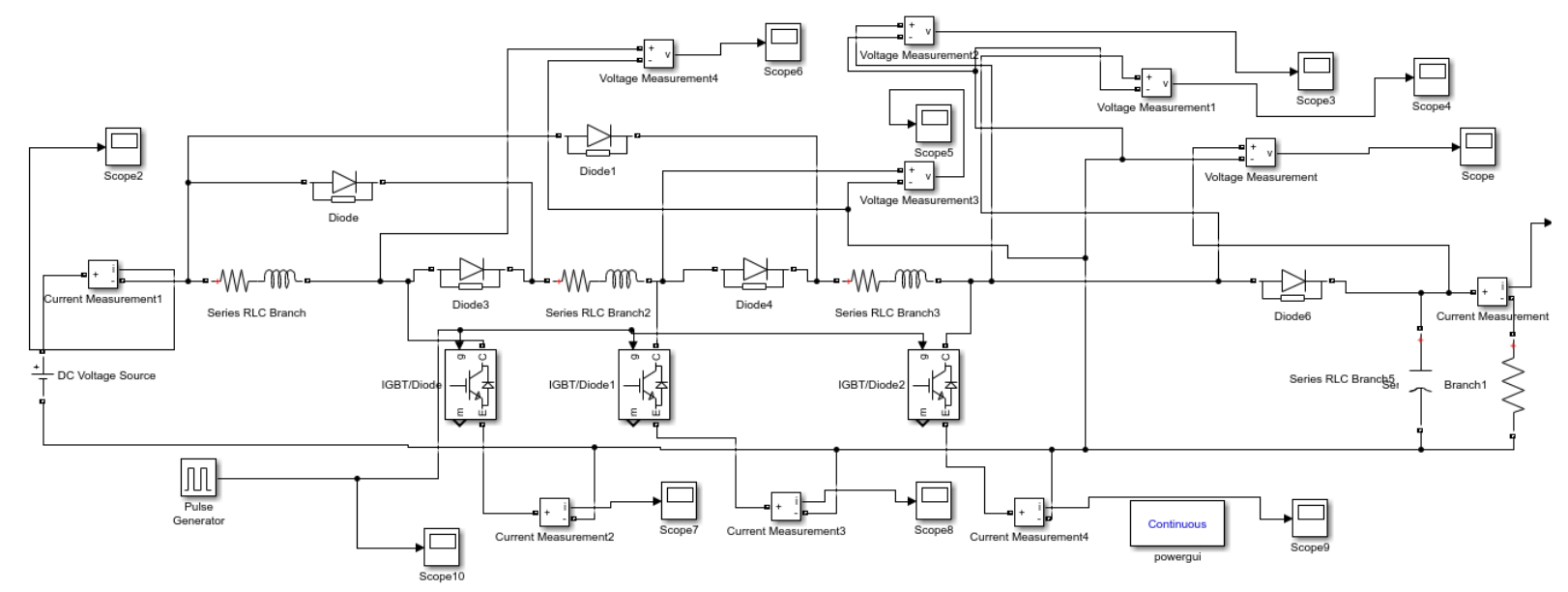

Fig. 11. Step up converter circuit.

The designed step up converter photograph is shown in Fig.(12).

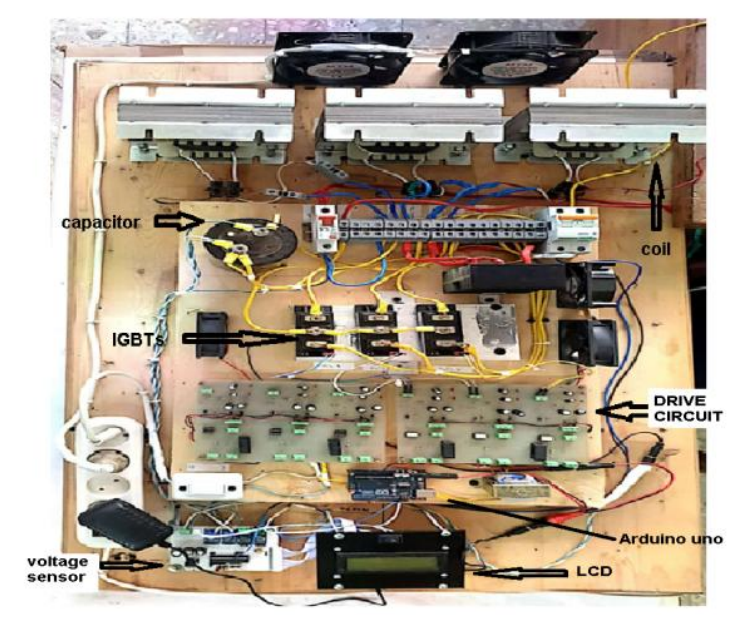

Fig. 12. The photograph of the designed converter

\section{MAT LAB SIMULATION}

The designed elements of the converter are simulated together as the design converter circuit using mat lab. Fig: (11) shows the mat lab simulation circuit of the designed converter. Three voltmeters are connected in the output of each coil of the converter. The voltmeter required the voltage from the output terminal of the coils to ground. Resistive load of $150 \mathrm{ohm}$ is connected to the terminals required $(120,210$ and 270). The voltmeter near to the DC supply voltage of the converter circuit (four series batteries of $12 \mathrm{~V}$ each) required 120 voltage. The second voltmeter required the voltage of the terminal of the middle coil required $210 \mathrm{~V}$. the third voltmeter near the load required $270 \mathrm{~V}$. the third voltmeter reads the terminal voltage of the load. The required data of the voltmeters represents that the voltage increases non linearly from the first stage of the converter (near the supply voltage). The second stage and to the third stage near to the load. This phenomenal is logically occur because the three coil are connected in series during the discharge condition. The discharge circuit of each coil is in the two 
other coil as well as the load non the supply voltage is shorted. This means that the discharge the circuit of each coil is presented as in R-L circuit the nonlinear circuit.

\section{A. Mat lab simulation results}

1) The output current of the supply voltage (batteries) is required against time by the mat lab simulation as shown in Fig. (13).

Fig.(13): represent that the current initial from point with a value of nearly ( 0.3 ampere). This value of the current represents the steady state condition the circuit (without operation of the switch). As the switch operate, the transit condition of the operation occur. The last condition the current goes up to value near to 90 ampere during the interval 6 second. During the last interval the coil is in charging conditions. The coil becomes full charge during 6 second. This means that the coil is not full charge during $(\mathrm{t}=$ ton). On the other hand, it becomes full charge after several cycle of the triggering frequency $(10 \mathrm{kHz})$ with duty cycle (0.7).

\section{2) Supply voltage}

The source of power of the design of converter contains four batteries of $12 \mathrm{~V}$ each. Hence, the terminal voltage of the power source is 48 VDC lead acid batteries fig: (14) illustrates the terminal voltage of the supply against time.
The figure shows that, the supply voltage constant during the process of charging and discharging condition of the coils.

\section{3) IGBT Current}

The design converter contains three switch of the IGBT type. The three switches are similar of characteristics. Hence, the current of charging and discharging of each a witch is the same for each other. Fig (15) represent the relation shape between the current of the switch against time during the charging and discharging condition of the coils. The fig illustrates that the current during the two process has two pulses during the charging and discharging the current of rise exponent. It takes a function of,

$$
i=I\left(1-e^{-(t / \tau)}\right)
$$

Where;

$\mathrm{i}:$ is the instantaneous current value,

I: is the max. value of the current equal of 30 ampere,

$\tau$ : is the time constant in second, and IGBT.

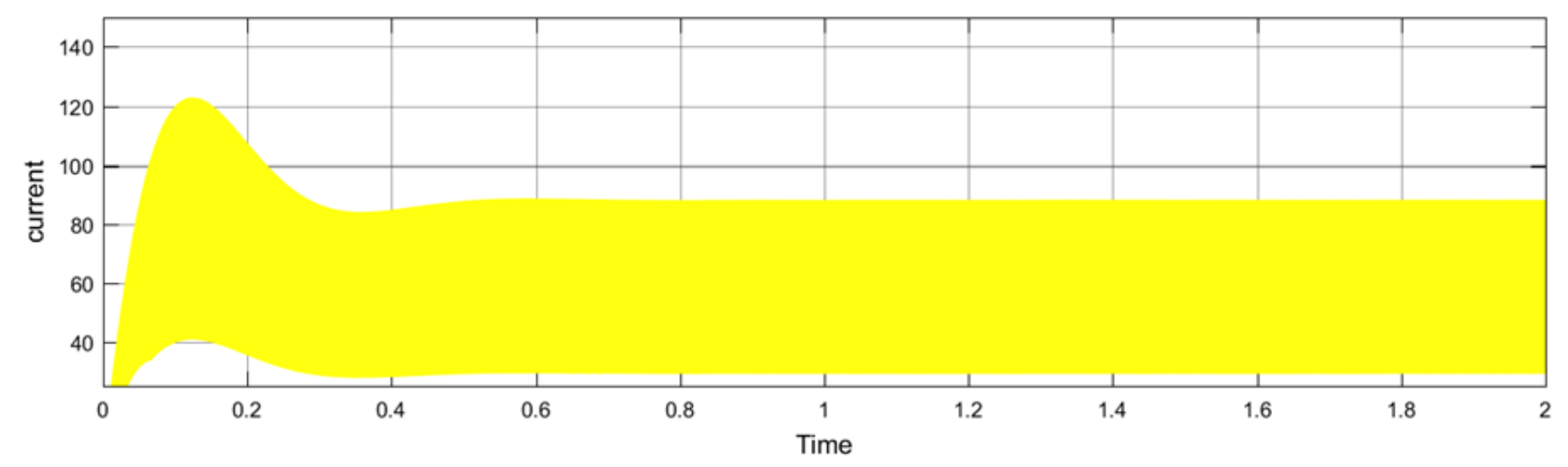

Fig. 13. Current supply against time

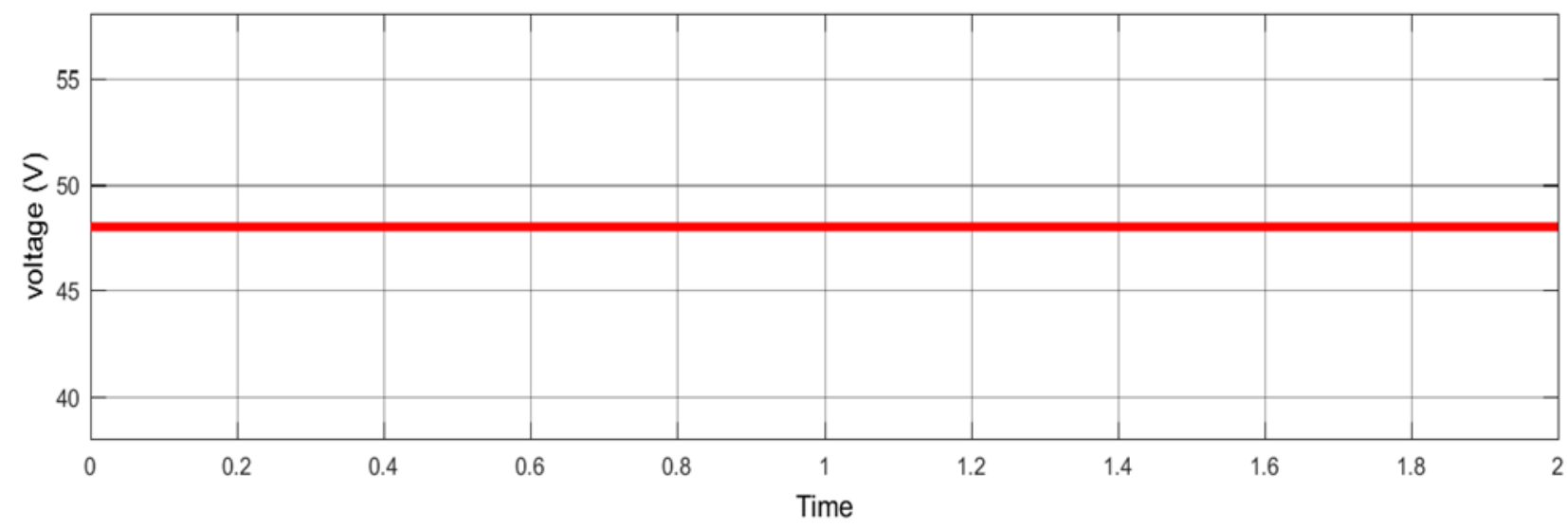

Fig. 14. Voltage supply 


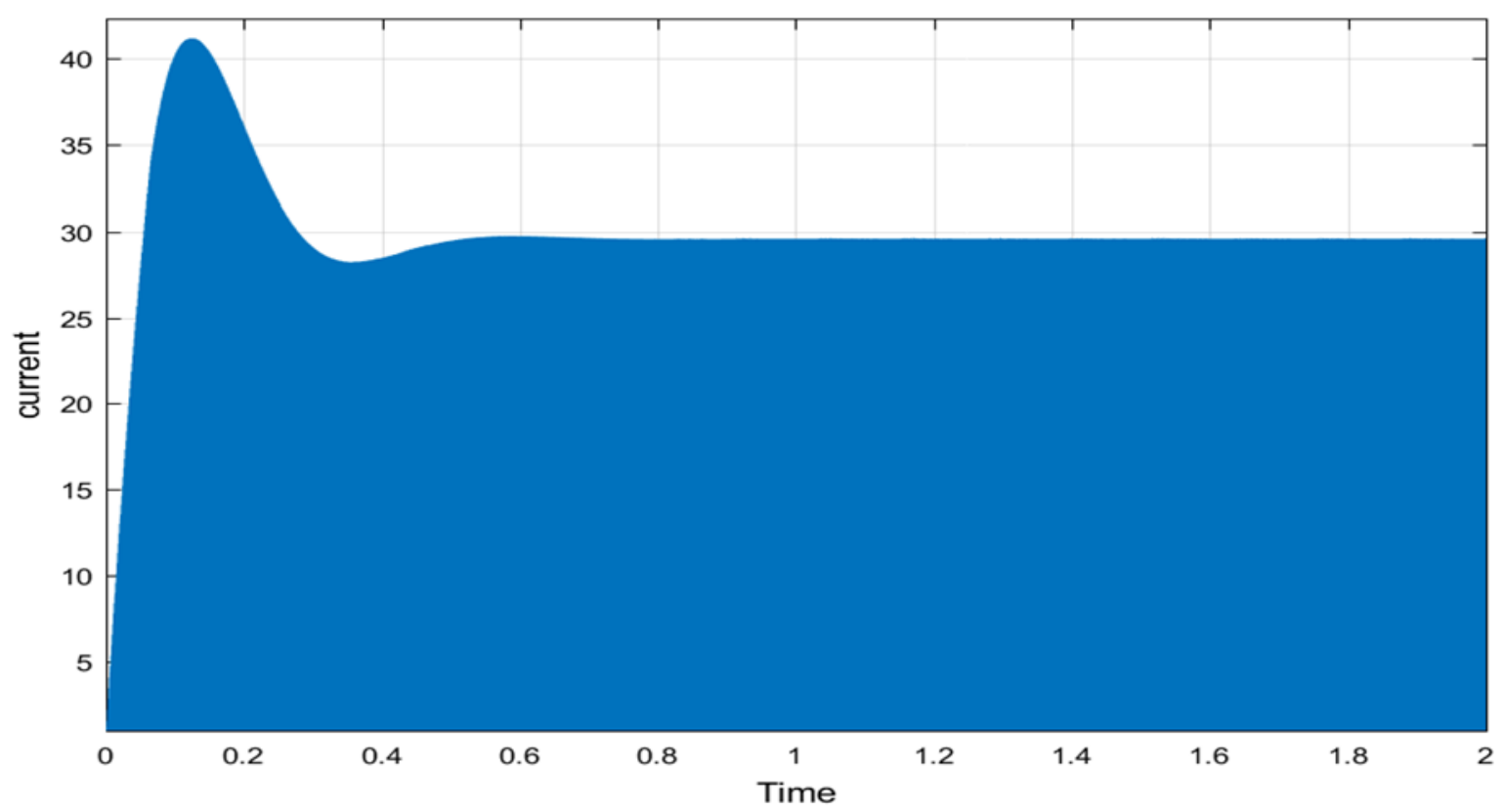

Fig. 15. IGBT current against time

The charging circuit of each IGBT of the converter contains $\mathrm{R}$ and $\mathrm{L}$ elements so, the time constant of the charging circuit of each IGBTs is equal to (L/R) second. fig (15) shows that the max. value of the charging current of IGBT is nearly equal to 30 ampere. Fig (13) shows that the max. Value of the current dropping from the supply during the charging conditions is nearly equal to 90 ampere. This means that the charging current of each IGBT has the same value during the discharging condition the current IGBT switch has a pulse setting form. The discharging current behaves as coming down exponent function. It behaves as the flowing equation ;

$$
\begin{gathered}
i= \\
I e^{-t / \tau}
\end{gathered}
$$

\section{Where:}

$i$ i: is the value of discharging current,

I: is the max. value of the discharging current,

$\mathrm{I}=30$ ampere, and

$\mathrm{T}:$ is the time constant of the discharging circuit, it is equal to (L/R).

The later Fig. shows the final value of the discharging current. It reaches to its minimum of nearly 0.1 ampere. The Fig. shows that the last value of current is less than the minimum value of source current as shown in fig (15).

4) Collector and emitter voltage of converter switches.

Fig (16), (17) and (18) describe the collector and emitter voltage of converter switches, the three Figures take the same shape.

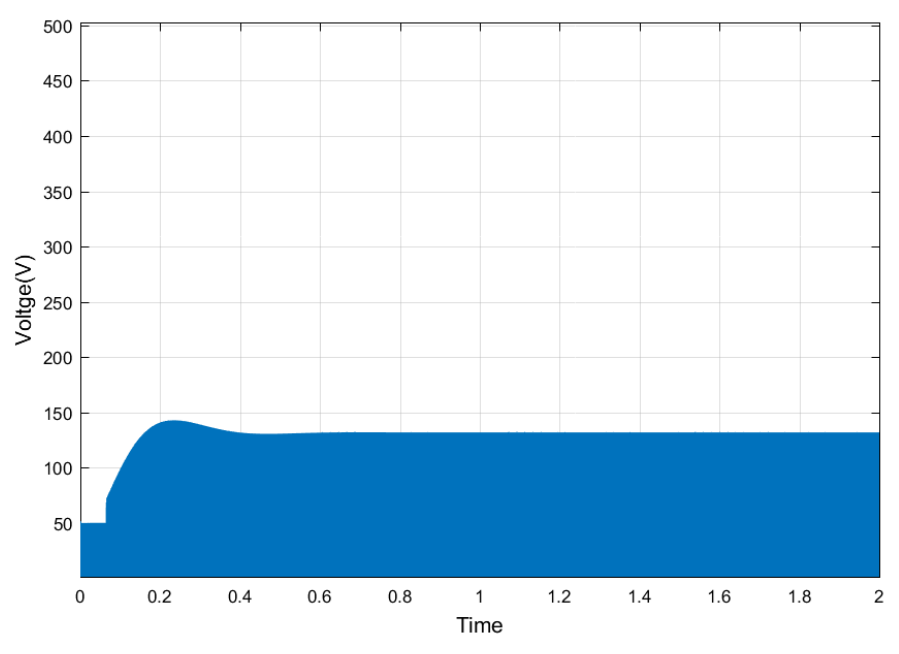

Fig. 16. Voltage IGBT1 against time

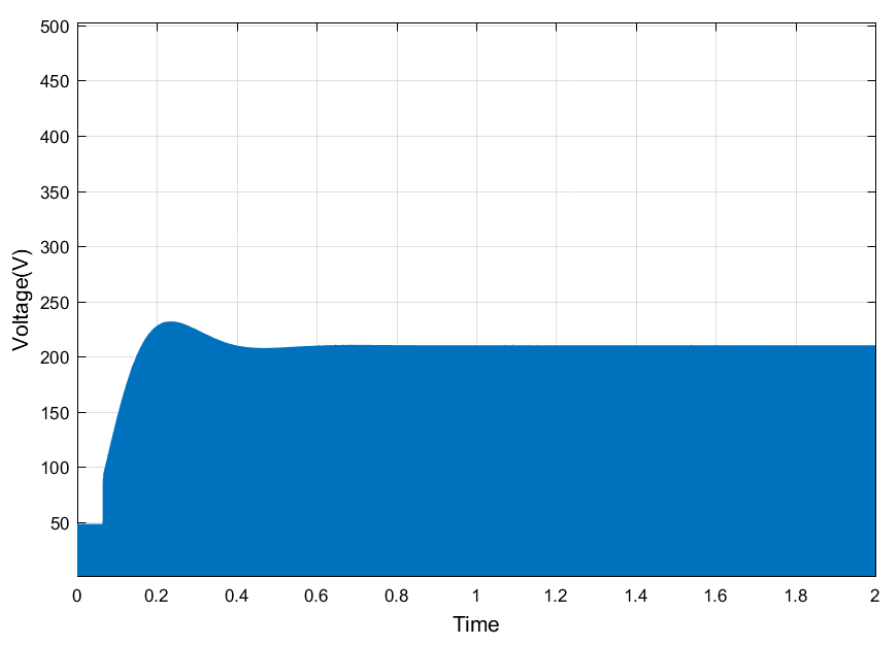

Fig. 17. Voltage IGBT2 against time 


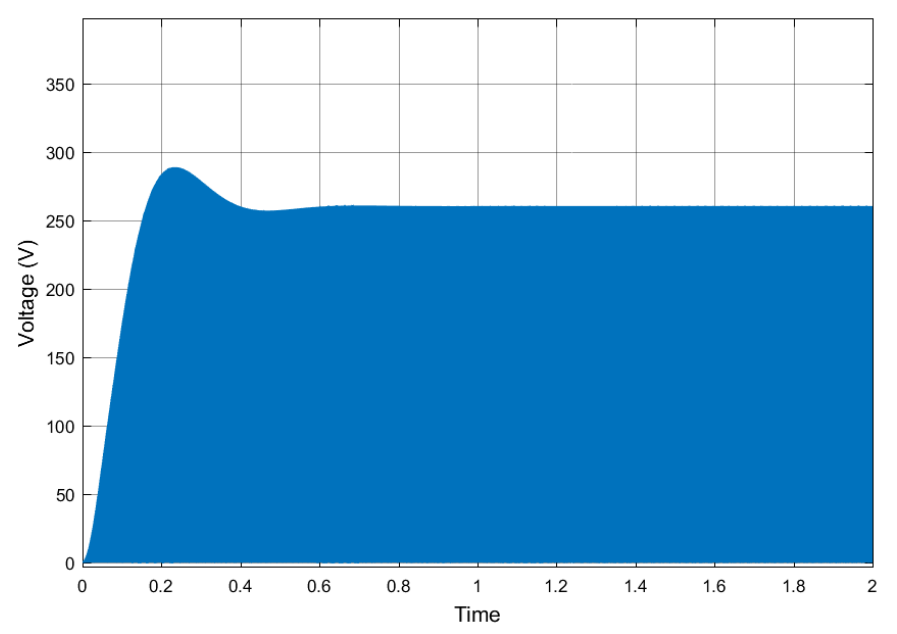

Fig. 18. Voltage of IGBT3

On the other hand, it has different amplitude value. Fig.(16) represent that the voltage (VCE) of IGBT1 rises from zero to value near equal to the supply voltage (48 VDC). The voltage coill (nearly to supply) begins to charge. This means that the initial voltage of charge is equal to the supply voltage (48VDC). So, the charging- condition is in sheet. The coil takes in travel of time equal to 6 second to complete the charging process. This in travel of charging time is equal to several cycle of switching. So , during each cycle of charging the voltage (VCE) of the switch goes up a above the value of the supply voltage. Hence, the max. value of the switch voltage reaches to nearly $120 \mathrm{~V}$. During 6 second interval the voltage takes rectangular pulse forms. This means that initially the voltage rise up for interval equal to the allowable to time for training on switch. During the switch of time its voltage fills down to a value of the supply voltage (48) during the next in travel of the allowable on time of the switch, the voltage is continued rise up. This process is repeated during the in travel of 6 second and the voltage. Of the switch rises to it is max. (120VDC). Fig: (18) is similar in the shape of the Fig: (17) on the other hand, the peak of voltage of switch coil 2 (middle switch) reaches to a value of (210) the Fig: (16) shows that the initial value of voltage of the second switch has the same value of the first switch (nearly the supply). It has value of near to $48 \mathrm{~V}$ also. This is due to the fact of , the three switches are connected in parallel during $(\mathrm{ON})$ condition. The max. value voltage of the collector and emitter middle switch has a max. value more greater than the max. value of the voltage switch 1 (nearly supply) it has a value (210 VDC).

\section{5) Load current}

Fig.(19) illustrate the load current at different time. The Fig. shows the DC value of nearly 0.2 ampere. Than it goes up to its maximum value of 10 ampere during 6 seconds after that, the current takes its maximum value of (10 ampere depend on the load value).

\section{Practical Operation The Designed CONVERTER.}

The design of the boost converter is practically operated and loaded by resistive load. The load consists of four resistances of $50 \mathrm{ohm}$ each. The resistor are grouped into two groups. Each group has two resistor connected in series. On the other hand, the groups are connected parallel. Fig.(20) represent the load resistor.

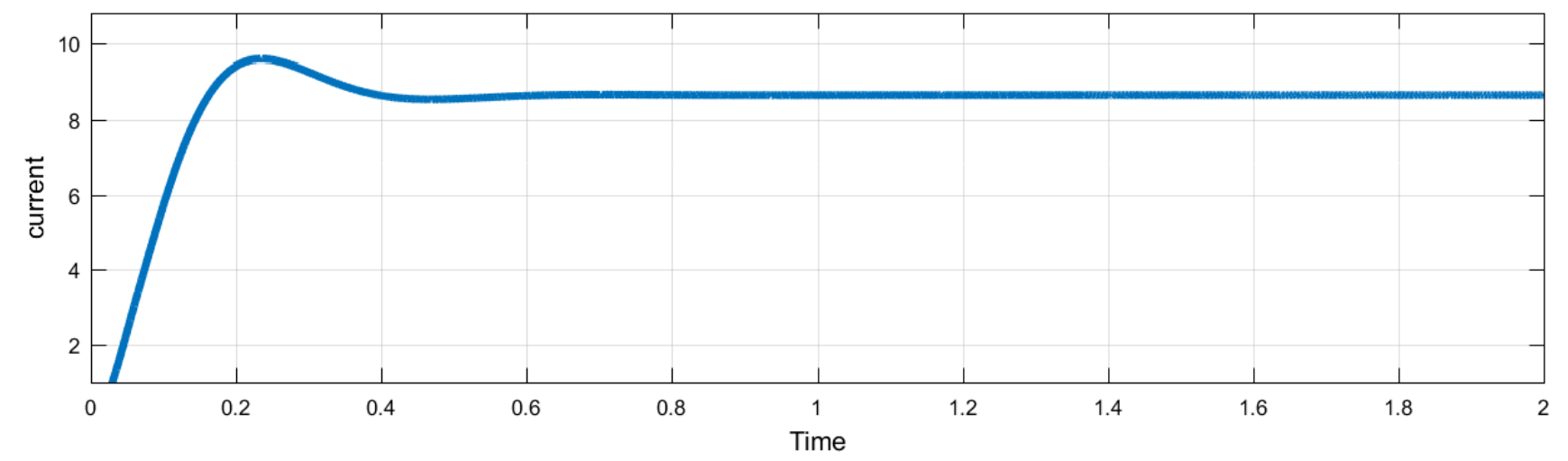

Fig. 19. Load Current

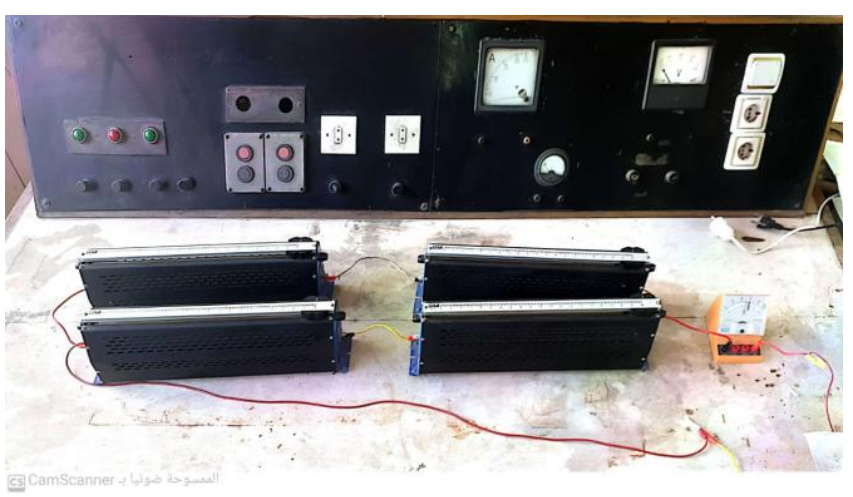

Fig. 20. Load Resistor.
The duty cycle is gradually increased from zero to $85 \%$. The output voltage of the converter across the load is measured by a digital voltmeter. As the duty cycle increases, the output voltage also increases from 48 VDC (supply voltage) as the duty cycle equal to zero. The duty cycle is initialize with the value of 0.1 and increases gradually with steps equal to 0.1 . The output voltage increases to $320 \mathrm{VDC}$ at duty cycle equals to $75 \%$. The $75 \%$ duty cycle reverse to the peak value of the output voltage of (320 VDC). As the duty cycle increases from the optimum value of $(75 \%)$ the output voltage of the converter decreases. Hence, the value of $75 \%$ of duty cycle has the optimum value of it. So, the design of the converter must be operate at the last optimum value $75 \%$ Fig (21)shows the relationship between the design converter output voltage and the duty cycle. 


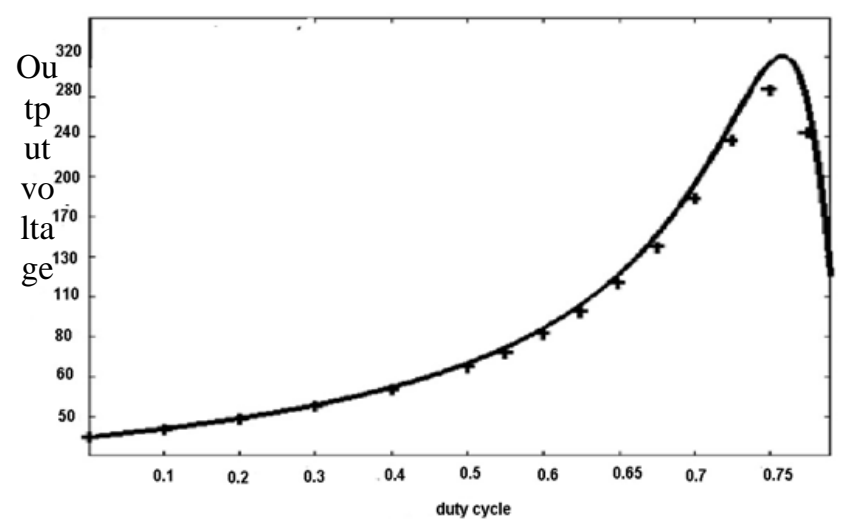

Fig. 21. The relation between output voltage and duty cycle

The output of the converter increases as the duty cycle is increases. This is due to the fact that, the duty cycle increase the frequency remain constant. So the on time is gradually increases. This means that the average directly output voltage of the converter increases. The designed the converter is connected directly to the load. The also output voltage is recorded. As the load increases, the current increases also and its voltage will decreases. Hence, the output voltage must be controlled by a control circuit [29]. Fig (22) represents the control system used to stability the converter output voltage at value. This value is selected the range of (as the load is three phase equal to (320 to 360) VDC. For single-phase load the voltage is fixed at (220 to 240) VDC. The control range of the duty cycle is in the range of ( 0.1 to $0.75)$.

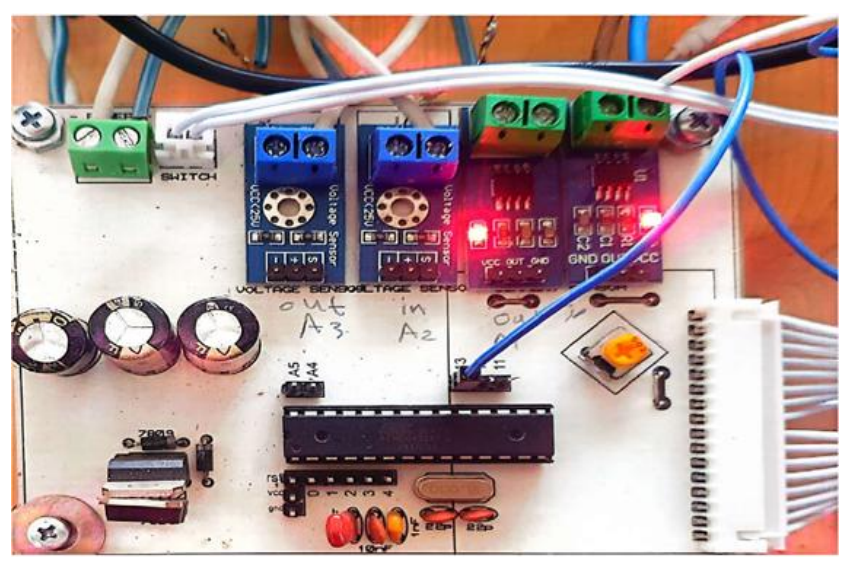

Fig. 22. Control system

\section{COnClusions.}

This is paper the design of a DC/DC boost converter rising up the DC voltage of $48 \mathrm{~V}$ to $320 \mathrm{VDC}$ or desired value. The converter circuit is initialed consecrated and it is elements are connected with each other. The designed converter has three stages. Each stage consists coil, diode, and electronic switch. The last switch is taken as the IGBTs type. The three coils are charged and discharged through the three circuits. The three stages of the converter are connected in parallel during the charging conditions of the coils. On the other hand, during the discharge condition the three stages are connected are series to hence the converter output voltage to the designed level required. Suitable switch ratings are selected according to the load data. The coil is designed according to the load data as well as to the switching frequency selected. $10 \mathrm{KHz}$ of the switching frequency suitable charging and discharging condition suitable optimum value of duty cycle is selected according to the converter. $0.75 \%$ optimum duty cycle is selected. Hence, the converter operates at a duty cycle less than or equal to the optimum value selected. The iron core of the coil is selected to prevent the leakage flux from passing the air. Hence the coil reactance is lower to the minimum level. So, the (MMF) required to force the magnetic flux through the iron core is lowered. To the minimum level also. The wire of the coil is selected according to the correct density of the load (current load). The suitable capacitor is used to in hence the load current of the converter at instances of lowering the voltage auto coil. A suitable diode grid is selected to prevent the reactive power between the coils or to the 48 VDC supply. The drive circuit of the switches is designed. The ARDUINO is used as a pulses generator, generates pulses to each switch according to the design strategy of operation. Drives circuits are selected to reach the pulses generated from the ARDUINO to the gates of the switches. The pulse generator from ARDUINO has a frequency of $10 \mathrm{KHz}$. The suitable control system is designed to control the converter output voltage at no load and at load conditions hence the ARDUINO has designed from the output voltage of the converter. So according to the selecting level of the output voltage, the ARDUINO strategy selects the best value of the duty cycle of operation at different load levels. So the output voltage of the converter remains to consist at different load levels as well as at the open circuit condition. Mat lab simulation of the designed converter is a simulation is built up to show the electrical performance of the converter at different load levels of resistive static load. The simulator shows that the dc output voltage of the converter floats nearly $600 \mathrm{vdc}$ at no load to nearly $300 \mathrm{vdc}$ as the load current equal to 10 amperes the simulator circuits operate at the duty cycle fixed to value $0.75 \%$. the operation converter depend on the load level. As the load current increases the converter output voltage decreases. The designed converter is practically loaded with static and dynamic DC load. The control system is connected between the converter output terminals and ARDUINO input. The variable strategy of the ARDUINO operation is designed to change the duty cycle from the level selected to the optimum level. The DC output voltage of the convert is required and measured by the oscilloscope. As well as the measuring in (voltmeter and ammeter). The static load changes and the voltage is required. The dynamic load (DC motor) is loaded to the converter. The motor load is changed and the terminal voltage of the converter is required. The practical operation of the converter couple with the static as well as the dynamic loads shows the successful operation of the control system. The terminal voltage of the converter to the loads remains constants during the operation of the load at the different levels and types. The reaction system based upon PV systems or PV systems content batteries is provided with suitable systems to hence the DC voltage to suitable levels. Same systems of PV type contains AC transformers to a cheap previous propose. This is an old method used. The upto-date method achieving the last proposal is the design of a suitable DC/DC converter. The dc converter is used to increases the dc voltage input to the PV system to suitable levels the converter is finally coupled with $\mathrm{dc}-\mathrm{ac}$ inverter hence the designed converter is this chapter coupled with a $5.5 \mathrm{~kW}$ single-phase inverter successfully coupling and operation the inverter as well as the converter achieved. The control system is operated according to the design strategy max the voltage remains constant at the level of load. 


\section{REFERENCES}

[1] Y. Chen, C. Chen and Z. Shao, "A DC-DC boost converter with high voltage gain for distributed generation," 2016 IEEE 5th Global Conference on Consumer Electronics, 2016, pp. 1-2, doi: 10.1109/GCCE.2016.7800382.

[2] M. Ghanbari and S. M. Hosseini, "DC/DC boost converter design and development based on asynchronously paralleled switches," 2008 IEEE International Conference on Industrial Technology, 2008, pp. 15, doi: 10.1109/ICIT.2008.4608713.

[3] M. Eydi, S. H. Hosseini and R. Ghazi, "A New High Gain DC-DC Boost Converter with Continuous Input and Output Currents," 2019 10th International Power Electronics, Drive Systems and Technologies Conference (PEDSTC), 2019, pp. 224-229, doi: 10.1109/PEDSTC.2019.8697693.

[4] S. Antony and S. P. Sathiyan, "Design and simulation of boost converter with input ripple cancellation network," 2015 IEEE International Conference on Electrical, Computer and Communication Technologies (ICECCT), 2015, pp. 1-6, doi: 10.1109/ICECCT.2015.7225967.

[5] R. J. K. Prasana, S. Ramprasath and N. Vijayasarathi, "Design and analysis of hybrid DC-DC boost converter in continuous conduction mode," 2016 International Conference on Circuit, Power and Computing Technologies (ICCPCT), 2016, pp. 1-5, doi: 10.1109/ICCPCT.2016.7530166.

[6] H. M. Solaiman, M. M. Hasan, A. Mohammad, S. R. Kawsar and M. A. Hassan, "Performance analysis of DC to DC boost converter using different control methods," 2015 IEEE International Conference on Electrical, Computer and Communication Technologies (ICECCT), 2015, pp. 1-5, doi: 10.1109/ICECCT.2015.7226007.

[7] A. R. Nikhar, S. M. Apte and R. Somalwar, "Review of various control techniques for DC-DC interleaved boost converters," 2016 International Conference on Global Trends in Signal Processing, Information Computing and Communication (ICGTSPICC), 2016, pp. 432-437, doi: 10.1109/ICGTSPICC.2016.7955340.

[8] M. Premkumar, C. Kumar, A. Anbarasan , R. Sowmya , "A novel non-isolated high step-up DC-DC boost converter using single switch for renewable energy systems," Springer- 2020.

[9] Mirza Fuad Adnan, Mohammad Abdul Moin Oninda, Mirza Muntasir Nishat, Nafiul Islam, 2017, "Design and Simulation of a DC - DC Boost Converter with PID Controller for Enhanced Performance", INTERNATIONAL JOURNAL OF ENGINEERING RESEARCH \& TECHNOLOGY (IJERT) Volume 06, Issue 09 (September 2017), http://dx.doi.org/10.17577/IJERTV6IS090029.

[10] Y. Jiang, M. Law, Z. Chen, P. Mak and R. P. Martins, "Algebraic Series-Parallel-Based Switched-Capacitor DC-DC Boost Converter With Wide Input Voltage Range and Enhanced Power Density," in IEEE Journal of Solid-State Circuits, vol. 54, no. 11, pp. 3118-3134, Nov. 2019, doi: 10.1109/JSSC.2019.2935556.

[11] Andreas J., Setiawan E.A., Halim S., Atar M., Shabrina H.N., 2018." Performance Test of $2.5 \mathrm{~kW}$ DC Boost Converter for Nanogrid System Applications", International Journal of Technology. Volume 9(6), pp. 1285-1294.

[12] Thandar Aung, Tun Lin Naing, "DC-Link Voltage Control of DC-DC Boost Converter-Inverter System with PI Controller," World Academy of Science, Engineering and Technology International Journal of Electrical and Computer Engineering Vol:12, No:11, 2018.

[13] G. Wang, F. Wang, G. Magai, Y. Lei, A. Huang and M. Das, "Performance comparison of 1200V 100A SiC MOSFET and 1200V 100A silicon IGBT," 2013 IEEE Energy Conversion Congress and Exposition, 2013, pp. 3230-3234, doi: 10.1109/ECCE.2013.6647124.

[14] A. Tulbure, D. Turschner, M. Abrudean, E. Ceuca and R. Ormenisan, "Experimental comparation of switching with IGBT and MOSFET," 2010 IEEE International Conference on Automation, Quality and Testing, Robotics (AQTR), 2010, pp. 1-5, doi: 10.1109/AQTR.2010.5520804.
[15] I. D. de Vries, "A resonant power MOSFET/IGBT gate driver," APEC. Seventeenth Annual IEEE Applied Power Electronics Conference and Exposition (Cat. No.02CH37335), 2002, pp. 179-185 vol.1, doi: 10.1109/APEC.2002.989245.

[16] Yan Hu, Renyuan Tang, Xiulian Wang, Liangyun Zhao and Zhenyan Guo, "The analysis and calculation of the magnetic flux density distributions in a 3-phase roll-iron core transformer," Sixth International Conference on Electrical Machines and Systems, 2003. ICEMS 2003., 2003, pp. 790-793 vol.2.

[17] B. Gaussens, B. Chareyron and A. Abdelli, "Flux-Density Calculation in Ferromagnetic Parts of Field-Excited Switched-Flux Machines Using Fourier Analysis," 2018 21st International Conference on Electrical Machines and Systems (ICEMS), 2018, pp. 2649-2654, doi: 10.23919/ICEMS.2018.8549124.

[18] A. Hilal and B. Cougo, "Optimal inductor design and material selection for high power density inverters used in aircraft applications," 2016 International Conference on Electrical Systems for Aircraft, Railway, Ship Propulsion and Road Vehicles \& International Transportation Electrification Conference (ESARSITEC), 2016, pp. 1-6, doi: 10.1109/ESARS-ITEC.2016.7841359.

[19] Y. Han and D. J. Perreault, "Inductor design methods with lowpermeability RF core materials," 2010 IEEE Energy Conversion Congress and Exposition, 2010, pp. 4376-4383, doi: 10.1109/ECCE.2010.5618453.

[20] Q. Li, M. A. E. Andersen and O. C. Thomsen, "Research on Power Factor Correction boost inductor design optimization - Efficiency vs. power density," 8th International Conference on Power Electronics - ECCE Asia, 2011, pp. 728-735, doi: 10.1109/ICPE.2011.5944650.

[21] M. Lu, Y. Xie, W. Zhu, A. Peyton and W. Yin, "Determination of the Magnetic Permeability, Electrical Conductivity, and Thickness of Ferrite Metallic Plates Using a Multifrequency Electromagnetic Sensing System," in IEEE Transactions on Industrial Informatics, vol. 15, no. 7, pp. 4111-4119, July 2019, doi: 10.1109/TII.2018.2885406.

[22] S. C. Tang, S. Y. Hui and H. S. -. Chung, "Evaluation of the shielding effects on printed-circuit-board transformers using ferrite plates and copper sheets," in IEEE Transactions on Power Electronics, vol. 17, no. 6, pp. 1080-1088, Nov. 2002, doi: 10.1109/TPEL.2002.805585.

[23] C. Cuellar, W. Tan, X. Margueron, A. Benabou and N. Idir, "Measurement method of the complex magnetic permeability of ferrites in high frequency," 2012 IEEE International Instrumentation and Measurement Technology Conference Proceedings, 2012, pp. 6368, doi: 10.1109/I2MTC.2012.6229697.

[24] E. Macrelli et al., "Modeling, Design, and Fabrication of HighInductance Bond Wire Microtransformers With Toroidal Ferrite Core," in IEEE Transactions on Power Electronics, vol. 30, +no. 10, pp. 5724-5737, Oct. 2015, doi: 10.1109/TPEL.2014.2370814.

[25] A. Brockmeyer and J. Paulus-Neues, "Frequency dependence of the ferrite-loss increase caused by premagnetization," Proceedings of APEC 97 - Applied Power Electronics Conference, 1997, pp. 375-380 vol.1, doi: 10.1109/APEC.1997.581478.

[26] A. Kumar, R. K. Mandal, R. raushan and P. gauri, "Design and Analysis of the Gate Driver Circuit for Power Semiconductor Switches," 2020 International Conference on Emerging Frontiers in Electrical and Electronic Technologies (ICEFEET), 2020, pp. 1-6, doi: 10.1109/ICEFEET49149.2020.9186960.

[27] J. Xu and K. Han, "The Single-Phase Inverter Design for Photovoltaic System," 2016 International Symposium on Computer, Consumer and Control (IS3C), 2016, pp. 341-344, doi: 10.1109/IS3C.2016.95.

[28] Y. A. Badamasi, "The working principle of an Arduino," 2014 11th International Conference on Electronics, Computer and Computation (ICECCO), 2014, pp. 1-4, doi: 10.1109/ICECCO.2014.6997578.

[29] Kiam Heong Ang, G. Chong and Yun Li, "PID control system analysis, design, and technology," in IEEE Transactions on Control Systems Technology, vol. 13, no. 4, pp. 559-576, July 2005, doi: 10.1109/TCST.2005.847331. 